\title{
Hobbes e a pandemia hipotética no Leviatã: entre a liberdade e a segurança
}

\author{
Hobbes and the hypothetical pandemic in Leviathan: \\ between freedom and security
}

Jairo Rivaldo Silva ${ }^{1}$

1 Professor de Filosofia Geral e Jurídica no Centro Universitário Maurício de Nassau em Caruaru-PE. Mestre em Filosofia pela UFPE. E-mail: jairorivaldo@gmail.com Orcid: http://orcid.org/0000-0002-0598-7583

RESUMO: O aparecimento do coronavírus fez ressurgir um antigo debate no âmbito da filosofia política: o debate entre liberdade e segurança. A maioria dos países atingidos precisou adotar medidas que restringiram a liberdade dos cidadãos para conter o avanço da doença. Esse artigo tem o objetivo de apresentar a posição do filósofo inglês, Thomas Hobbes exposta no Leviatã, para enfrentar esse problema. O texto está dividido em três partes. Em um primeiro momento, apresento a tese de Hobbes sobre a segurança e contra a liberdade irrestrita para evitar o estado de natureza. Em um segundo momento, apresento a tese de Hobbes sobre a liberdade limitada no estado político. Por fim, apresento uma possível solução para conjugar liberdade e segurança a partir do conceito hobbesiano de razão pública.

Palavras-chave: Liberdade. Segurança. Coronavírus. Pandemia. Estado de Natureza. Leviatã.

ABSTRACT: The emergence of the coronavirus raised up an old problem within the scope of political philosophy: the debate between liberty and security. Most affected countries had to adopt measures that limited citizens' liberty to restraint the spread of the disease. This article aims to present the position of the English philosopher, Thomas Hobbes exposed in Leviathan, to face this problem. The text is divided into three parts. At first, I present Hobbes' thesis on security and against unrestricted liberty to avoid the state of nature. In a second step, I present Hobbes' thesis on limited liberty in the political state. Finally, I present a possible solution to combine liberty and security based on the Hobbesian concept of public reason.

Key words: Liberty, Security. Coronavirus. Pandemic. State of Nature. Leviathan.

\section{Introdução}

Com o aparecimento do coronavírus os países atingidos precisaram adotar medidas drásticas como a restrição da liberdade e do direito de ir e vir dos seus cidadãos. No Brasil, as recentes medidas restritivas tomadas por alguns governadores, em alguns estados da federação, produziram uma série de reações e reacenderam um antigo debate no âmbito da filosofia política e das ciências sociais, a saber, o debate entre a liberdade e a segurança. A liberdade deve ser preservada independente de qualquer circunstância? Qual é o papel do Estado em situações que ameacem a segurança dos cidadãos? O que deve prevalecer em momentos de desordem social, a liberdade ou a segurança? Liberdade e segurança são sempre antitéticos?

O presente artigo tem o objetivo de apresentar a posição do filósofo inglês, Thomas Hobbes no Leviatã, para enfrentar esse problema. O texto está dividido em três partes. Em um primeiro momento, apresento a tese de Hobbes sobre a necessidade de segurança e contra a liberdade ilimitada no hipotético "estado de mera natureza" apresentado por Hobbes no capítulo XIII do Leviatã. Em um segundo momento, 
analisarei os quatro tipos de liberdade que Hobbes apresenta no capítulo XXI do Leviatã e como eles se expressam em um estado político. Finalmente, apresentarei uma proposta para minimizar a antinomia entre liberdade e segurança a partir do conceito hobbesiano de razão pública recentemente reinterpretado por S. A. Lloyd e Mark Button.

\section{Liberdade e segurança no estado de natureza}

Uma das preocupações centrais no pensamento de Hobbes era o problema de como manter a estabilidade política de uma República. Isso significa dizer, como observa Lloyd, que a ciência civil desenvolvida por Hobbes, especialmente no Leviatã, "busca evitar o problema da desordem social causada, sobretudo, pelos interesses morais transcendentes dos cidadãos” (1922: 1), dentre eles, o interesse na liberdade. Assim, antes de acusá-lo de defender um sistema despótico e desumano, é importante estar consciente desse ponto de partida da sua teoria política a fim de entender o que o seu modelo teórico está tentando evitar.

O clássico capítulo XIII do Leviatã de Hobbes nos transporta a um estado ou condição hipotética que ele denomina de estado de mera natureza (condition of mere nature) (HOBBES, 1996: 91), e que os teóricos políticos posteriores, chamados de contratualistas, passarão a ser referir (cada uma a seu modo) como o estado de natureza. Apesar das diversas interpretações sobre se esse estado deveria ser considerado literal ou não, entendo que "a condição natural ou estado de guerra não é uma frase que se lê literalmente. Tratase de uma 'hipótese da razão', uma construção lógica, para exprimir uma situação em que os homens viveriam se não houvesse um senhor comum para subjugá-los”. (MAGALHÃES, 2014: 51).

De acordo com Hobbes, a vida nessas condições seria "solitária, miserável, sórdida, brutal e curta". (HOBBES, 2014: 109). Nesse estado, todos teriam liberdade irrestrita e direito a todas as coisas, mas, dada à escassez dos recursos e os desejos ilimitados das pessoas, teríamos, de acordo com Hobbes, a receita perfeita para a anarquia e a desordem. No estado de natureza hobbesiano há uma busca incessante pelos interesses individuais em detrimento de qualquer cooperação ou preocupação com a segurança coletiva e, mesmo individual. Entretanto, segundo a perspectiva de Hobbes, o resultado de desprezar a segurança em nome da liberdade não pode ser outro além de uma vida curta.

A solução hobbesiana para evitar o estado pandêmico é o estabelecimento de um árbitro público (public reason) capaz de garantir a segurança de todos em troca de obediência e da transferência de alguns direitos, que no estado de natureza seriam ilimitados. Com o estabelecimento desse árbitro, qualquer ameaça à vida social o autoriza a, ocasionalmente, impor sanções e mesmo punir fisicamente os que, por conta do seu egoísmo, ameaçarem a estabilidade da República. (HOBBES, 2014: 154). Como destaco em O Leviathan de Hobbes em Nova Perspectiva:

o pressuposto de que os cidadãos são motivados pelo egoísmo psicológico é o responsável pelo conflito de interesses que resultará no benefício de um e no prejuízo do outro. É justamente isso que acontece no estado de natureza hobbesiano. A racionalidade instrumental, com a qual são guiados os seres humanos, faz com que a cooperação voluntária seja menos provável no estado de natureza, pelo fato de que parece mais racional e vantajoso (dado o interesse básico que guia os seres humanos) evitar um acordo e obter uma vantagem unilateral, do que firmar um acordo de cooperação e obter vantagens "menores". (SILVA, 2020: 98).

A racionalidade instrumental, que parece caracterizar os seres humanos no estado de natureza hobbesiano, tende a ser a característica básica que guia os indivíduos em momentos análogos ao estado 
hipotético descrito por Hobbes. Em momentos de crise, uma espécie de razão instrumental leva os indivíduos a elaborar seus próprios juízos particulares e a perseguir seus próprios fins em detrimento dos outros.

Contudo, como nos lembra Gauthier, se cada um exigir que sua própria razão seja tomada como certa, então a consequência será a guerra de todos contra todos. A solução para essa situação de conflito e medo permanente seria transferir o locus da deliberação individual para um árbitro ou razão pública a quem transferimos nosso direito natural. (GAUTHIER, 1995: 27). Desse modo, o tradicional mecanismo do contrato social entre os cidadãos cujo único interesse racional em momentos de desordem é a autopreservação, é, em suma, a solução do problema da desordem social. Assim, somente um árbitro público, que aqui pode ser traduzido como um Estado forte pode, pela ameaça de sanções e pelo uso da força, fazer com que haja obediência, cooperação, segurança e ordem social.

Mutatis mutandi, a situação descrita no estado de natureza pode ser comparada ao cenário surreal que o mundo atual está enfrentando com o aparecimento da COVID-19. O isolamento social e a consequente paralisação dos mercados mundiais colocaram em evidência o que Hobbes chamaria de interesses na autopreservação ou, simplesmente, o lado egoísta dos seres humanos. No Brasil, com poucos dias de isolamento social, diversos atos de desobediência civil (tendo a liberdade para justificá-los) em forma de protestos, carreatas e aglomerações de pessoas nas ruas, reivindicavam a abertura do comércio e a volta da normalização do modo de vida capitalista.

$\mathrm{Na}$ maioria dos estados brasileiros os governadores implantaram, via decreto, o isolamento social, o fechamento do comércio e a proibição de eventos de qualquer natureza para evitar a aglomeração de pessoas. A conclusão que se segue do argumento de Hobbes para evitar o estado de natureza é, a priori, que a segurança e a ordem social em momentos de crise devem ter prioridade sobre os interesses individuais como o interesse na liberdade.

Todavia, a fim de evitar uma conclusão apressada e mesmo simplista sobre o que Hobbes entende por liberdade, examinarei em seguida o capítulo XXI do Leviatã que é dedicado ao tema da liberdade, sua definição, natureza, extensão e limites. O objetivo é responder às seguintes questões: por que, em Hobbes, a segurança deve preceder a liberdade? Tem mesmo que ser assim? Em troca de que é necessário sacrificar a liberdade no altar da segurança?

\section{A liberdade dos cidadãos no estado político}

Antes de apresentar o que Hobbes entende por liberdade no capítulo XXI do Leviatã, é importante contextualizar o debate em que ele estava envolvido com os republicanos na Inglaterra do século XVII. Em obra dedicada ao tema, Quentin Skinner apresenta o desenvolvimento da concepção de liberdade do filósofo inglês como uma reação ao movimento republicano, cujo a concepção de liberdade tinha o seguinte teor: “(...) a simples presença de um poder arbitrário é suficiente para subverter a liberdade no seio das associações civis, porque tem por efeito reduzir os membros de tais associações do status de homens livres ao de escravos". (2010: 10).

Os republicanos, que se opunham à monarquia Stuart, objetavam que vários dos seus direitos e liberdades estavam sendo solapados pela política legal e fiscal da monarquia absolutista de Carlos I. Segundo Skinner, a resposta de Hobbes, com o seu capítulo sobre a liberdade no Leviatã, bem como toda a sua teoria política, é uma intervenção polêmica nos conflitos ideológicos do seu tempo. (SKINNER, 2010: 14). Seja como for, a elaboração conceitual sobre a liberdade desenvolvida por Hobbes é relevante até hoje.

No capítulo XXI do Leviatã, Hobbes apresenta ao menos quatro sentidos ou tipos de liberdades: 1) 
liberdade como ausência de impedimentos externos; 2) liberdade total ou direito de natureza; 3) liberdade civil; 4) liberdade como direito inalienável.

O primeiro sentido ou tipo de liberdade, que para Hobbes é a própria definição de liberdade, é a “ausência de oposição (entendendo por oposição os impedimentos externos do movimento), e não se aplica menos às criaturas irracionais e inanimadas do que às racionais". (HOBBES, 2014: 179). Uma pessoa acorrentada ou trancada em uma cela de prisão não tem liberdade nesse sentido; as correntes e paredes são impedimentos externos que se opõem ao movimento de uma pessoa. Isso é corroborado pela explicação adicional que o próprio Hobbes oferece após a sua definição: "porque de tudo o que estiver amarrado de modo que não se possa mover senão dentro de um certo espaço, sendo esse espaço determinado pela oposição de algum corpo externo, dizemos que não tem liberdade de ir mais além”. (Ibidem.). Contudo, esse tipo de liberdade não é algo restrito aos seres humanos; os animais não humanos e os seres inanimados como pedras impedidas de rolar ou águas represadas, que de outra sorte se espraiariam, podem ser considerados livres ou não livres nesse sentido. Há ainda uma última observação importante nesse primeiro sentido de liberdade apresentado por Hobbes. Segundo Susanne Sreedhar, para Hobbes, a falta de liberdade não é o mesmo que impotência; para Hobbes, a impotência é uma questão de impedimentos internos ao movimento. "Uma pessoa paralisada da cintura para baixo não tem o poder de dar a volta no quarteirão; enquanto um prisioneiro na cadeia não tem a liberdade de fazê-lo”. (SREEDHAR, 2013: 185).

O segundo tipo de liberdade, que aqui denomino liberdade total ou direito de natureza, pode também ser classificado como ausência de pactos ou laços artificiais. (Ibidem.). Em outras palavras, é o tipo de liberdade encontrada no estado de mera natureza descrito por Hobbes no capítulo XIII do Leviatã e que foi transferido pelos súditos para o soberano no momento da instituição da República. Hobbes o define assim na abertura do capítulo XIV:

O direito de natureza, a que os autores geralmente chamam Jus Naturale, é a liberdade que cada homem possui de usar o seu próprio poder, da maneira que quiser, para a preservação da sua própria natureza, ou seja, da sua vida; e consequentemente de fazer tudo aquilo que o seu próprio julgamento e razão lhe indiquem como meios mais adequados a esse fim. (HOBBES, 2014: 112).

É importante distinguir entre o primeiro sentido de liberdade e o segundo apresentado acima. Enquanto no primeiro sentido é livre quem não for impedido externamente; a característica básica do segundo tipo de liberdade é a reivindicação de agir segundo o seu próprio juízo privado, uma espécie de autonomia que não seria obstaculizada por nenhum tipo de impedimento, seja externo, seja interno. A resposta de Hobbes aos que defendiam esse tipo de liberdade é que ela é perigosa, e que se fosse concedida aos cidadãos, eles seriam conduzidos ao estado de anarquia e violência que ninguém racional deveria desejar. Hobbes zomba daqueles que buscam esse segundo tipo de liberdade dizendo que "não é menos absurdo que os homens exijam". (HOBBES, 2014: 181).

O terceiro tipo de liberdade que Hobbes apresenta nesse capítulo é a liberdade civil. De acordo com Sreedhar, "esse é o sentido mais importante de liberdade que Hobbes busca justificar em uma República. Esse tipo de liberdade pode ser definido como a liberdade de agir de acordo com o próprio julgamento em circunstâncias não regidas pela lei civil”. (SREEDHAR, 2013: 186). Aqui, Hobbes ressalta um aspecto importante da sua tese sobre a liberdade em um estado político: as leis civis, chamadas por ele também de laços artificiais que servem como parâmetros para o exercício da liberdade em uma República. Para Hobbes, a extensão da liberdade em um estado político é sempre a mesma, seja em um estado popular, seja em uma monarquia. (HOBBES, 2014: 184). Isso ocorre pelo fato de que a liberdade dos cidadãos em qualquer estado 
político consiste "em todas as espécies de ações omitidas pelas leis (...) para fazer o que a razão de cada um sugerir”. (Ibidem.).

Hobbes cita uma série de atividades que poderiam ser legitimamente empreendidas por qualquer cidadão no caso de não haver lei civil anterior que as regulamente:

(...) a liberdade dos súditos está apenas naquelas coisas que, ao regular as suas ações, o soberano preteriu: como a liberdade de comprar e vender, ou de outro modo realizar contratos mútuos; de cada um escolher a sua residência, a sua alimentação, a sua profissão, e instruir seus filhos conforme achar melhor, e coisas semelhantes. (2014: 182).

Em outras palavras, a liberdade civil é a liberdade circunscrita ao ambiente privado. Como observa Sreedhar, "como seus exemplos acima ilustram, sua concepção de liberdade civil inclui muitas das coisas que agora associaríamos ao ideal liberal da esfera privada do indivíduo, ou seja, aquelas que nos dão a capacidade de dirigir nossas vidas de acordo com nossas escolhas". (SREEDHAR, 2013: 186). Todavia, mesmo em questões notadamente consideradas privadas a partir da reforma protestante do século XVI, como a escolha da religião particular, Hobbes defende que deve haver um controle por parte do Estado no que diz respeito ao conteúdo do discurso religioso quando este não estava afinado ao principal objetivo da República: a manutenção da paz.

No Prefácio do Leviatã, Hobbes denomina o discurso religioso subversivo como "fortificações avançadas do inimigo”. (2014: 6). No contexto da Inglaterra do século XVII, a multiplicidade de seitas cristãs que interpretavam as Escrituras frequentemente contra o governo e a grande adesão por parte do povo às ideias supostamente sancionadas por uma autoridade maior (como Deus) são os grandes responsáveis por essa postura totalitária do Estado hobbesiano. Segundo Hobbes, o soberano deveria se preocupar com as instâncias responsáveis pela formação e difusão das opiniões em uma República:

Pertence à soberania ser juiz de quais as opiniões e doutrinas são contrárias à paz, e quais as que lhe são propícias. E, em consequência, de em que ocasiões, até que ponto e o que se deve conceder àqueles que falam a multidões de pessoas, e de quem deve examinar as doutrinas de todos os livros antes de serem publicados. Pois as ações dos homens derivam das suas opiniões, e é no bom governo das opiniões que consiste o bom governo das ações dos homens, tendo em vista a paz e a concórdia entre eles. E embora em matéria de doutrina não se deva olhar para nada senão para a verdade, nada se opõe à sua regulação em função da paz. (HOBBES, 2014: 152).

O pressuposto para a censura no Estado hobbesiano é a preocupação com a paz e a estabilidade política. Isso fica evidente na citação acima quando Hobbes afirma que as ações dos homens derivam das suas opiniões, e é no bom governo das opiniões que consiste o bom governo das ações dos homens. Em suma, diante da anarquia que pode ser desencadeada caso o Estado não intervenha, Hobbes entende que a limitação da liberdade, mesmo aquelas que hoje são consideradas direitos fundamentais, é um preço pequeno a pagar.

O quarto e último tipo de liberdade a que Hobbes faz referência no capítulo XXI do Leviatã é também chamado por ele de verdadeira liberdade dos súditos. Trata-se de algo excepcional na sua teoria e acontece apenas quando o soberano ordena determinadas coisas que os súditos "podem sem injustiça recusar-se a fazer". (HOBBES, 2014: 185).

Os exemplos fornecidos por Hobbes são os seguintes:

(...) Já no capítulo XIV mostrei que os pactos no sentido de cada um se abster de defender o seu próprio corpo são nulos. Se o soberano ordenar a alguém (mesmo que justamente condenado) que se mate, se 
fira ou se mutile a si mesmo, ou que não resista aos que o atacarem, ou que se abstenha de usar os alimentos, o ar, os medicamentos, ou qualquer outra coisa sem a qual não poderá viver, esse alguém tem a liberdade de desobedecer. Se alguém for interrogado pelo soberano ou por sua autoridade, relativamente a um crime que cometeu, não é obrigado (a não ser que receba garantia de perdão) a confessá-lo, porque ninguém (conforme mostrei no mesmo capítulo) pode ser obrigado por um pacto a acusar-se a si próprio. (Ibidem: 185-186).

Em resumo, a abordagem de Hobbes sobre a liberdade consiste nos quatro tipos acima apresentados. Primeiro, a menos que alguém esteja fisicamente confinado, tem liberdade no sentido estrito da palavra; segundo, a liberdade total existe no estado de natureza e no soberano no estado político; terceiro, a liberdade civil permite que os cidadãos sejam livres em diversas áreas da vida, dependendo do sistema particular de leis sob as quais vivem; e quarto, existem liberdades inalienáveis que se recusam a obedecer ao soberano, mas, em Repúblicas bem governadas, elas raramente serão exercidas.

Enfim, tendo a concordar com John Rawls quando ele pontua que "a concepção política de Hobbes tende a deixar o leitor insatisfeito, pois o obriga a escolher entre o absolutismo e a anarquia, isto é, um soberano com poderes ilimitados e o estado de natureza". (RAWLS, 2012: 93). Mas, voltando à nossa problemática, talvez a abordagem maniqueísta de Hobbes seja o único modelo capaz de descrever a realidade que nos foi imposta com a chegada da pandemia do coronavírus.

Devemos nos apegar ao ideal de liberdade e desobedecer às autoridades civis, que nesse momento entendem que a segurança é mais importante para evitar a proliferação do vírus? Ou devemos renunciar à liberdade nesse momento porque a autopreservação é mais importante? Seria possível uma alternativa que resolvesse a antinomia entre liberdade individual e razão de Estado? Esse será o assunto do último tópico desse artigo.

\section{Razão pública e juízos privados no Estado hobbesiano}

O Estado hobbesiano é inevitavelmente absolutista. As circunstâncias o exigiam. Contudo, é possível que o clamor por liberdade absoluta levasse realmente a República ao anarquismo. Uma alternativa interpretativa intermediária e, sobretudo, não coercitiva, capaz de conjugar a liberdade dos cidadãos com os ditames regulatórios do soberano apareceu apenas recentemente na literatura especializada sobre Hobbes. ${ }^{1}$ Acredito que os princípios apresentados por essa abordagem são capazes de nos fornecer uma solução razoável que também possa ser aplicada em circunstâncias drásticas específicas (como o caso de uma pandemia), mesmo em democracias constitucionais, onde a liberdade é um direito fundamental.

Segundo essa abordagem, um modo de resolver esse problema reside em um entendimento alternativo do conceito hobbesiano de razão pública (public reason) que, tradicionalmente, é a razão de Estado que deve ser imposta (independe da aceitação de todas as pessoas) a fim de preservar a unidade estabilidade da República. (HOBBES, 2014: 374). Para Button (2008: 38), “o conceito de razão pública em Hobbes inclui tanto a lei civil quanto a instrução pública para uma vida virtuosa e cívica”. Ele afirma que esses dois métodos não visavam apenas a adesão exterior dos súditos, mas "uma espécie de cultivo ético e um entendimento mais profundo da justiça que fosse além da observância dos pactos, da coerção e do medo” (Ibidem).

Segundo Button, “a razão pública representa o meio institucional pelo qual os indivíduos com seus direitos naturais (como a liberdade) e seus juízos privados sobre os mais diversos assuntos, são

${ }^{1}$ Conf. LLOYD (1992); BUTTON (2008). 
transformados em súditos-cidadãos" (2008: 45), isto é, em pessoas que não somente possuem uma consciência privada, mas agora também participam do que ele denomina de consciência pública. Portanto, segundo esse autor, a razão pública em Hobbes "vai além de um poder coercitivo de direito público autorizado pelas pessoas - ela representa as crenças, normas e virtudes que com o tempo serão responsáveis por formar todo o entendimento de cidadania em uma República". (2008: 47).

Concordo com Button quando ele afirma que uma questão central para Hobbes (e normalmente ignorada) é como cultivar uma aceitação e uma apreciação da razão de Estado, de maneira que isso venha a ser percebido pelos cidadãos como uma virtude capaz de influenciar as ações e disposições da maioria dos membros da sociedade civil. Assim, a questão para Hobbes é como formar e influenciar julgamentos privados. Em outras palavras, como transformar súditos em cidadãos.

Em sintonia com a abordagem de Button, Lloyd sustenta que a razão pública não seria eficaz se fosse estabelecida (pela força e apelando para a necessidade de segurança) apenas temporariamente. De acordo com ela, "mais importante do que o seu estabelecimento seria a sua manutenção". (LLOYD, 1992: 27). Todavia, isso só seria possível através de um processo contínuo de educação visando a obediência e o cultivo de virtudes cívicas. A razão para esse projeto transformativo reside no fato de que os cidadãos possuem juízos privados e interesses morais diversos (como o interesse na liberdade) que, caso não fossem educados, levariam a República de volta ao estado de natureza. Segundo Lloyd, esse estado hipotético não ocorre apenas numa condição pré-política, mas é capar de emergir mesmo no estado político:

(...) estar numa condição de "mera natureza" é estar em uma condição em que cada homem está medindo o bem e o mal por seu próprio apetite privado. O estado de natureza não é definido pela ausência do governo; ele é definido pela ausência do julgamento público do bem e do mal - uma medida pública do bem e do mal - que é providenciada em um Estado pelo governo. Assim, estar em um estado de natureza acontece quando cada um é governado pelo seu próprio julgamento privado - e esse estado pode estar presente não apenas na ausência de qualquer governo ou, antes mesmo, da instituição do governo, mas também na presença do governo [principalmente] se existir outro poder que desafia sua autoridade. (LLOYD, 1992: 261).

De fato, o exercício universal dos juízos privados é uma das principais razões pelas quais o estado da natureza é tão horrível. O direito de agir inteiramente de acordo com o seu próprio julgamento privado (ou direito à liberdade), é precisamente o que as pessoas renunciam quando formam o contrato social para entrar no estado político. Agora, como membros da sociedade civil, as pessoas devem renunciar aos seus direitos de governar a si mesmas e, em vez disso, devem adequar seus juízos privados à razão pública a fim de preservar a unidade da República.

É evidente que estou consciente de que essa solução seja contraintuitiva, mais ainda quando a proposta é transferí-la para o contexto atual brasileiro, que nas últimas eleições elegeu um presidente supostamente mais alinhado ao discurso liberal econômico e com bandeiras menos intervencionistas. Contudo, diante da ameaça de contaminação pela COVID-19, parece mais razoável que a liberdade de ir e vir e de comércio sejam, temporariamente, suspensas pelo Estado. Assim como a solução hobbesiana, a coerção não deve ser o primeiro passo, mas quando a conscientização não é suficiente e falta o compromisso com a cidadania por parte dos cidadãos, o Estado deve intervir para estabelecer a ordem.

\section{Considerações finais}

A vida precede a liberdade. Embora a sentença pareça óbvia, a questão é bem mais complexa. A tese 
de Hobbes não foi aceita sem relutância pelos seus contemporâneos. Até hoje seu nome carrega o estigma do erastianismo e do absolutismo, embora seja também considerado um dos percussores do liberalismo político. O fato é que não existem respostas simples para problemas complexos, ainda mais quando os problemas não se restringem ao âmbito teórico, mas afetam concretamente as vidas dos envolvidos, como é o caso da liberdade e da segurança.

Como deve ter ficado evidente, a premissa hobbesiana é de que a liberdade não deve ser ilimitada sob nenhuma circunstância. No estado de natureza ela abreviaria a vida, no estado político ela causaria a desordem. Em momentos de crise (como a que estamos vivenciando), a liberdade precisa ser reeducada, reconfigurada e mesmo temporariamente renunciada, a fim de servir à um ideal maior, o ideal de cidadania e cooperação com as leis civis a fim de evitar a extinção da sociedade.

\section{Referências}

BUTTON, Mark E. 2008. Where Justice is called a Virtue: public reason and civic formation in Thomas Hobbes. In. Contract, Culture, And Citzenship. Transformative Liberalism from Hobbes to Rawls. University Park, Pennsylvania: Pennsylvania State University Press.

GAUTHIER, David P. 1995. Public Reason. In. Social Philosophy and Policy Foundation. 1969. The Logic of Leviathan: the moral and political theory of Thomas Hobbes. Oxford: Oxford University Press.

HOBBES, Thomas. 2014. Leviatã. $3^{\mathrm{a}}$ ed. São Paulo: Martins Fontes.

LLOYD, S. A. 1992. Ideals as interests in Hobbes's Leviathan: The power of mind over matter. Cambridge: Cambridge University Press.

MAGALHÃES, Fernando. 2014. 10 Lições Sobre Hobbes. Petrópolis, RJ: Vozes.

RAWLS, John. 2012. Conferências sobre a História da Filosofia Política. São Paulo: Martins Fontes.

SILVA, Jairo Rivaldo da. 2020. O Leviathan de Hobbes em Nova Perspectiva: um estudo sobre o papel dos pressupostos na interpretação. Belo Horizonte - MG: Editora Dialética.

SKINNER, Quentin. 2010. Hobbes e a Liberdade Republicana. São Paulo: Unesp.

SREEDHAR, Susanne. 2013. Liberty. In. LLOYD, S. A. The Bloomsbury Companion to Hobbes. New York/London: Bloomsbury companions.

Artigo recebido em: 25 de abril de 2020

Artigo aceito em: 01 de junho de 2020 